\title{
Influence of Sun Drying and Sucrose on Adventitious Root Development from Pineapple Crown
}

\author{
Harikrishan Deb and Ankan Das*
}

Department of Horticulture, Institute of Agricultural Science, University of Calcutta, Kolkata, West Bengal, India

*Corresponding author: ankandas660@gmail.com (ORCID ID: 0000-0002-0946-2653)

Paper No. 927

Received: 04-06-2021

Revised: $12-08-2021$

Accepted: 23-09-2021

\begin{abstract}
The experiment was carried to study the influence of sun-drying and sucrose on adventitious root development from pineapple crown. Crowns were sun-dried \& treated with sucrose concentrations of $2 \%, 4 \%$ \& $0 \%$ respectively. Pineapple crowns were dipped in the sucrose solution and kept in ambient condition. There were six treatments that were replicated thrice in Completely Randomized Design. The sucrose solution was changed after every third day to avoid microbial contamination. Multiple parameters were studied at different intervals. From the whole experiment, it can be said that the treatments with $4 \%$ sucrose \& without sun drying proved to most affluent in case of every aspect in adventitious root development of pineapple crown.
\end{abstract}

\section{HIGHLIGHTS}

(0 Pineapple crown treated with four percent sucrose without any prior sun drying was found the best with respect to different attributes.

Keywords: Pineapple, crown, drying, sucrose, study

Pineapple (Ananas comosus) is one of the commercial fruit crops of India which belongs to the family bromeliaceae. Pineapple is a good source of Vitamin A \& Vitamin C and is relatively rich in Vitamin $B_{1}$ and Vitamin $B_{2}$. It contains the enzyme bromelin, and several odorous lactones have also been found in pineapple. Root growth in pineapple commences soon after planting and continues up until around flowering. Root development slows but continues throughout winter, depending on temperatures and soil moisture. Although bromeliads have a weakly developed, fragile root system which perhaps can be traced back to their epiphytic ancestry, pineapple roots can infiltrate to a depth of 1.5 $\mathrm{m}$. The number of underground roots depends on the weight and type of planting material, and crowns produce considerably more roots than slips or suckers. Adventitious root development is a complex procedure that is stimulated by numerous internal components, including phytohormones and environmental factors (Xuan et al. 2008). Several studies have been organized to induce adventitious root growth in different planting materials of pineapples, including crown. Here, in this work, different concentrations of sucrose were used as rooting media for pineapple crown, which shows contrasting results, some in length growth, some in diameter growth, number of leaves, etc. Besides these, the present experiment was also undertaken to observe the impact of sun-drying in the growth of crown root in pineapple. Therefore the experiment deals with sun drying and various sucrose concentrations in different aspects of adventitious root growth from pineapple crown.

How to cite this article: Deb, H. and Das, A. 2021. Influence of Sun Drying and Sucrose on Adventitious Root Development from Pineapple Crown. IJAEB, 14(03): 405-409.

Source of Support: None; Conflict of Interest: None (क) 


\section{MATERIALS AND METHODS}

This experiment was carried out in the Department of Horticulture, Institute of Agricultural Science, the University of Calcutta in the month of MayJune (2021). The average temperature during the experiment was in between $32-34^{\circ} \mathrm{C}$, and the relative humidity was near about $85 \%$. In order to prepare the treatments, 18 crowns were taken that were detached from freshly bought pineapples fruits; hence 18 disposal plastic cups were also taken to culture those crowns \& one pack of $500 \mathrm{gm}$ sucrose was used too. As for the required study, half of the crowns were dried about 7-8 hrs/day in the sunlight for 4 days before the application of treatments, while the rest halves were directly treated without any drying. Before undergoing the required treatments, from both half of the crowns, the lower leaves were peeled off up to an extent so that the white basal portion of the crown was visible. The treatments used for the study were $T_{1}$ : 0 Day Drying $+2 \%$ sucrose, $\mathrm{T}_{2}: 4$ Day Drying $+2 \%$ sucrose, $\mathrm{T}_{3}: 0$ Day Drying $+4 \%$ sucrose, $\mathrm{T}_{4}: 4$ Day Drying $+4 \%$ sucrose, $\mathrm{T}_{5}: 0$ Day Drying $+0 \%$ sucrose and $\mathrm{T}_{6}: 4$ Day Drying $+0 \%$ sucrose. The design for the experiment was a Completely Randomized Design (Gomez and Gomez 1984; Sheoran et al. 1998). Each of the treatments had 3 replications and was dipped in respective sucrose solutions, and the solutions were changed in every 3 days of interval until all the readings were taken. There are six different parameters viz. the first emergence of roots, number of roots, number of leaves, number of damaged leaves, length of roots, and diameter of roots were observed on $20^{\text {th }}, 25^{\text {th }} \& 30^{\text {th }}$ day from the day of dipping.

\section{RESULTS AND DISCUSSION}

\section{First Emergence of Roots}

From the perusal of data collected in Table 1, it is noticed that on average, each treatment took near about a week for the first rooting in the crown. The treatment $\mathrm{T}_{1}(0$ Day Drying $+2 \%$ sucrose $), \mathrm{T}_{3}(0$ Day Drying $+4 \%$ sucrose $) \& \mathrm{~T}_{5}(0$ Day Sun Drying $+0 \%$ sucrose) showed the early emergence while the treatment $\mathrm{T}_{2}$ (4 Day Drying $+2 \%$ sucrose), $\mathrm{T}_{4}(4$ Day Sun Drying $+4 \%$ sucrose) \& $\mathrm{T}_{6}$ (4 Day Drying $+0 \%$ sucrose) showed a bit late emergence of roots. Among them, $\mathrm{T}_{2}$ (4 Day Drying $+2 \%$ sucrose)
$\& \mathrm{~T}_{4}$ (4 Day Sun Drying $+4 \%$ sucrose) overdue the rooting most, whereas $\mathrm{T}_{1}(0$ Day Drying $+2 \%$ sucrose) was the earliest and the rest of the others appeared to be in quite a moderate position with rooting emergence.

Table 1: First emergence of pineapple crown as affected by sun-drying \& sucrose

\begin{tabular}{ll}
\hline Treatments & Day of emergence \\
\hline $\mathrm{T}_{1}$ & 5.67 \\
$\mathrm{~T}_{2}$ & 10.00 \\
$\mathrm{~T}_{3}$ & 6.33 \\
$\mathrm{~T}_{4}$ & 10.00 \\
$\mathrm{~T}_{5}$ & 6.00 \\
$\mathrm{~T}_{6}$ & 8.67 \\
\hline CD & $\mathbf{1 . 4 6 9}$ \\
\hline Sem $\underline{\mathbf{0 . 4 7 1}}$ & $\mathbf{0 . 4 7 1}$ \\
\hline
\end{tabular}

\section{Number of Leaves}

The recorded data shown in Table 2 has indicated that there was no significant impact of sucrose solution and only water in the increase or decrease of several leaves on $20^{\text {th }}, 25^{\text {th }} \& 30^{\text {th }}$ day after application of treatment. The number of leaves recorded in the initial stage, i.e., before the treatments, remains unchanged even after the application of every treatment till the last day of observation.

Table 2: Number of leaves in pineapple crown as affected by sun-drying \& sucrose

\begin{tabular}{llll}
\hline Treatments & 20 Days & 25 Days & 30 Days \\
\hline $\mathrm{T}_{1}$ & 26.00 & 26.00 & 26.00 \\
$\mathrm{~T}_{2}$ & 22.67 & 22.67 & 22.67 \\
$\mathrm{~T}_{3}$ & 27.00 & 27.00 & 27.00 \\
$\mathrm{~T}_{4}$ & 23.33 & 23.33 & 23.33 \\
$\mathrm{~T}_{5}$ & 26.67 & 26.67 & 26.67 \\
$\mathrm{~T}_{6}$ & 27.33 & 27.33 & 26.67 \\
\hline CD & $\mathbf{2 . 7 8 0}$ & $\mathbf{2 . 7 8 0}$ & $\mathbf{2 . 8 7 5}$ \\
\hline Sem $\boldsymbol{1}$ & $\mathbf{0 . 8 9 2}$ & $\mathbf{0 . 8 9 2}$ & $\mathbf{0 . 9 2 3}$ \\
\hline
\end{tabular}

\section{Number of Damaged Leaves}

Data presented in Table 3 showed that there was some influence of the treatments over this parameter, especially in $\mathrm{T}_{6}$ (4 Day Sun Drying + $0 \%$ sucrose $) \& \mathrm{~T}_{5}$ (0 Day Sun Drying $+0 \%$ sucrose $)$. It is observed that the number of damaged leaves gradually increases as compared to that present in the initial stage of the crown before application of 
any treatment. Whereas, in the initial stage, there was seen some damage due to the pre-treatment procedure of sun-drying in crowns in-case of $\mathrm{T}_{2}$ (4 Day Sun Drying + 2\% sucrose), $\mathrm{T}_{4}$ (4 Day Sun Drying $+4 \%$ sucrose), and $\mathrm{T}_{6}$ (4 Day Sun Drying $+0 \%$ sucrose). These numbers of damaged leaves remain unchanged once after the application of treatment which was recorded at $20^{\text {th }}, 25^{\text {th }} \& 30^{\text {th }}$ day. There was no further damage of leaves once treatments were applied.

Table 3: Number of damaged leaves in pineapple crowns as affected by sun-drying \& sucrose

\begin{tabular}{llll}
\hline Treatments & 20 Days & 25 Days & 30 Days \\
\hline $\mathrm{T}_{1}$ & 10.67 & 10.67 & 10.67 \\
$\mathrm{~T}_{2}$ & 9.00 & 9.00 & 9.00 \\
$\mathrm{~T}_{3}$ & 11.67 & 11.67 & 11.67 \\
$\mathrm{~T}_{4}$ & 10.67 & 10.67 & 10.67 \\
$\mathrm{~T}_{5}$ & 11.67 & 11.67 & 11.67 \\
$\mathrm{~T}_{6}$ & 11.67 & 11.67 & 11.67 \\
\hline CD & N/A & N/A & N/A \\
\hline Sem \pm & $\mathbf{1 . 5 5 8}$ & $\mathbf{1 . 5 5 8}$ & $\mathbf{1 . 5 5 8}$ \\
\hline
\end{tabular}

\section{Number of Roots}

The recorded data in Table 4 showed a significant change in the number of roots from the initial stage to the last day of observation. In most treatments, there was some change in the numbers, whereas no variation was also seen in some treatments. In $\mathrm{T}_{1}(0$ Day Drying $+2 \%$ sucrose $)$ the number of roots observed on the $20^{\text {th }}$ day is quite well \& further increases also in $25^{\text {th }}$ day and remains unchanged in the $30^{\text {th }}$ day. Here, in $\mathrm{T}_{2}$ (4 Day Drying $+2 \%$ sucrose), the number of roots in the $20^{\text {th }}$ day is low compared to other treatments and increases slightly in numbers at the $25^{\text {th }} \& 30^{\text {th }}$ day. $\operatorname{In~}_{3}(0$ Day Drying $+4 \%$ sucrose) the data indicates that the number of roots observed in the $20^{\text {th }}$ day was highest among all the other treatments and remains the same on the $25^{\text {th }} \& 30^{\text {th }}$ day. In $\mathrm{T}_{4}$ (4 Day Drying $+4 \%$ sucrose $)$, the observation directs that the growth in the number of roots is also low on the 20th day and increases slightly on the $25^{\text {th }}$ day, and remains the same up to the $30^{\text {th }}$ day. In the treatment $\mathrm{T}_{5}(0$ Day Drying $+0 \%$ sucrose), several roots in the $20^{\text {th }}$ day were higher than $\mathrm{T}_{6}$ (4 Day Drying $+0 \%$ sucrose) which was also treated with a pre-treatment procedure i.e. sun-drying. In both these treatments, the number of roots observed was unchanged in the following two observations.

Table 4: Number of roots in pineapple crowns as affected by sun-drying \& sucrose

\begin{tabular}{llll}
\hline Treatments & 20 Days & 25 Days & 30 Days \\
\hline $\mathrm{T}_{1}$ & 13.00 & 15.33 & 15.33 \\
$\mathrm{~T}_{2}$ & 10.00 & 10.33 & 11.00 \\
$\mathrm{~T}_{3}$ & 27.67 & 27.67 & 27.67 \\
$\mathrm{~T}_{4}$ & 10.33 & 11.67 & 11.67 \\
$\mathrm{~T}_{5}$ & 18.00 & 18.00 & 18.00 \\
$\mathrm{~T}_{6}$ & 16.00 & 16.00 & 16.00 \\
\hline CD & $\mathbf{1 0 . 8 5 9}$ & $\mathrm{N} / \mathrm{A}$ & $\mathrm{N} / \mathrm{A}$ \\
\hline Sem \pm & $\mathbf{3 . 4 8 5}$ & 3.988 & 4.021 \\
\hline
\end{tabular}

\section{Diameter of Roots}

From the data presented in Table 5 it was found that the diameter of roots has changed from day 25 to day 30 of observation in every treatment. In every observation, 1-3 roots were taken from each replication \& recorded as an average against their respective treatments. In $\mathrm{T}_{1}(0$ Day Drying $+2 \%$ sucrose $), \mathrm{T}_{3}(0$ Day Drying $+4 \%$ sucrose $) \&$ $\mathrm{T}_{5}$ (0 Day Sun Drying $+0 \%$ sucrose) the diameter measured was comparatively smaller than the diameter of $\mathrm{T}_{2}$ (4 Day Sun Drying $+2 \%$ sucrose), $\mathrm{T}_{4}$ (4 Day Drying $+4 \%$ sucrose) $\& \mathrm{~T}_{6}(4$ Day Drying + $0 \%$ sucrose). The maximum diameter was showed by $\mathrm{T}_{6}$ ( 4 Day Drying $+0 \%$ sucrose) followed by $\mathrm{T}_{5}$ (0 Day Sun Drying + 0\% sucrose), $\mathrm{T}_{4}$ (4 Day Drying $+4 \%$ sucrose $), \mathrm{T}_{3}(0$ Day Drying $+4 \%$ sucrose $), \mathrm{T}_{2}(4$ Day Sun Drying $+2 \%$ sucrose $) \& \mathrm{~T}_{1}$ (0 Day Drying $+2 \%$ sucrose).

Table 5: Diameter of roots ( $\mathrm{mm}$.) in pineapple crowns as affected by sun-drying \& sucrose

\begin{tabular}{llll}
\hline Treatments & 20 Days & 25 Days & 30 Days \\
\hline $\mathrm{T}_{1}$ & 0.94 & 1.06 & 1.03 \\
$\mathrm{~T}_{2}$ & 1.37 & 1.08 & 1.43 \\
$\mathrm{~T}_{3}$ & 0.90 & 1.16 & 1.03 \\
$\mathrm{~T}_{4}$ & 1.21 & 1.00 & 1.13 \\
$\mathrm{~T}_{5}$ & 1.27 & 1.39 & 1.32 \\
$\mathrm{~T}_{6}$ & 1.32 & 1.46 & 1.45 \\
\hline $\mathbf{C D}$ & $\mathbf{0 . 1 7 1}$ & $\mathbf{0 . 3 2 7}$ & $\mathbf{0 . 0 8 2}$ \\
\hline Sem \pm & $\mathbf{0 . 0 5 5}$ & $\mathbf{0 . 1 0 5}$ & $\mathbf{0 . 1 1 7}$ \\
\hline
\end{tabular}

Besides this, the diameter in all the treatments with pre-treatment procedure of sun-drying has shown better diameter growth than treatments without pre- 
treatment of sun drying. The results also indicate that T5 (0 Day Sun Drying + 0\% sucrose) \& T6 (4 Day Drying $+0 \%$ sucrose) have better diameter growth than others.

\section{Length of Roots}

The recorded data from Table 6 reflected that in every treatment, the length of roots gradually increased from the first observation ( $20^{\text {th }}$ day) to the third observation ( $30^{\text {th }}$ day). Among all the treatments, $\mathrm{T}_{1}$ (0 Day Drying $+2 \%$ sucrose $)$ has the highest root length in all 3 days of observation as collected, and $\mathrm{T}_{4}$ (4 Day Drying $+4 \%$ sucrose) has the lowest length growth of roots followed by $\mathrm{T}_{2}$ (4 Day Drying $+2 \%$ sucrose). On the contrary $\mathrm{T}_{5}$ (0 Day Drying + 0\% sucrose) \& $\mathrm{T}_{6}$ (4 Day Drying $+0 \%$ sucrose) has shown the moderate length of growth of roots along with $\mathrm{T}_{3}(0$ Day Drying + $4 \%$ sucrose). Here, it was seen that the treatments with sun-drying effect give negative impact in root development and it had also been found that less sucrose more root growth while the opposite outcome for more sucrose. That is why $\mathrm{T}_{4}$ (4 Day Drying $+4 \%$ sucrose) where sun-drying was most along with highest sucrose concentrations shows minimal root elongation. In contrast, in $\mathrm{T}_{1}(0$ Day Drying $+2 \%$ sucrose), the sucrose concentration was low and no sun-drying effect, giving the highest root elongation.

Table 6: Length of roots $(\mathrm{cm}$.) in pineapple crowns as affected by sun-drying \& sucrose

\begin{tabular}{llll}
\hline Treatments & 20 Days & 25 Days & 30 Days \\
\hline $\mathrm{T}_{1}$ & 3.02 & 3.22 & 3.96 \\
$\mathrm{~T}_{2}$ & 1.62 & 1.77 & 1.99 \\
$\mathrm{~T}_{3}$ & 2.17 & 2.40 & 3.00 \\
$\mathrm{~T}_{4}$ & 1.10 & 1.82 & 1.50 \\
$\mathrm{~T}_{5}$ & 2.16 & 2.37 & 2.70 \\
$\mathrm{~T}_{6}$ & 2.17 & 2.37 & 2.60 \\
\hline CD & $\mathbf{0 . 6 1 7}$ & $\mathbf{0 . 6 2 3}$ & $\mathbf{0 . 9 3 7}$ \\
\hline Sem \pm & $\mathbf{0 . 1 9 8}$ & $\mathbf{0 . 2 0 0}$ & $\mathbf{0 . 3 0 1}$
\end{tabular}

In this study, the effect of sun-drying \& sucrose concentration in detached pineapple crowns for root development has shown a significant effect in all parameters. The impact of sucrose solution is satisfactory in $\mathrm{T}_{1}(0$ Day Drying $+2 \%$ sucrose $)$ for early root emergence, which indicates that $2 \%$ sucrose was the fastest to push the growth. In comparison, intermediate results were obtained in $\mathrm{T}_{3}$ (0 Day Drying $+4 \%$ sucrose $) \& \mathrm{~T}_{5}$ (0 Day Sun Drying $+0 \%$ sucrose) that clearly shows the influence of $4 \%$ sucrose and water respectively in root arrival has not that much significance \& $\mathrm{T}_{2}(4$ Day Drying $+2 \%$ sucrose $), \mathrm{T}_{4}(4$ Day Drying $+4 \%$ sucrose) which shows very inferior outcomes in the appearance of roots. The rapid development of roots was since as the compound sucrose gives straight energy, it is a rich reservoir of carbohydrates (Dey et al. 2017). Although any concentrations of sucrose did not show any differences in the number of leaves or damaged leaves, likewise similarly, in a study, it was seen that sucrose concentration did not show any significant variability in lush growth i.e., leaves number or proliferation rate in fig cv. About (Elazab et al. 2015). Meanwhile, the treatments with sun-drying of crowns showed late root emergence. Where the 2\% sucrose showed the fastest root growth \& $4 \%$ sucrose showed the slowest.

On the other hand, $4 \%$ sucrose seems to be having the best effect incase of several roots, and $2 \%$ sucrose has the less effective in that. It was also seen that the sun-drying leads to fewer root counts, whereas $0 \%$ sucrose with water promotes the root counts. Similar work has been observed by Calamar and De Klerk, (2002) in apple. Sucrose in the rootgrowth medium is one of the prime components for both attaining a high rooting percentage and promoting root extension (Chenevard et al. 1995). $\mathrm{T}_{6}$ (4 Day Drying $+0 \%$ sucrose) helps to increase the diameter of roots where $2 \%$ sucrose restricts the promotion of diameter \& $4 \%$ sucrose with sundrying or without sun-drying has minimal impact on diameter growth. A similar experiment was carried out in sweet potato for tuberous root growth where plants were treated with different sucrose concentrations. The root diameter outreached 15 $\mathrm{mm}$ at the end of the 25-day cultivation (Eguchi and Yoshida 2008). Lastly, in the length of roots, $2 \%$ sucrose has the most impressive impact, $4 \%$ sucrose with sun-drying as pre-treatment has been shown the poor influence in all the 3 observations. Only water showed the length growth equally in each day of observation. Likewise, Kesari et al. (2010) did their work to analyze the influence of auxin in Pongamia pinnata for the promotion of root development. They concluded that it helped in root initiation, its elongation, and its number. Sucrose played an 
essential role as its main constituent carbohydrate is very much required for plant cellular construction. It provides excellent energy and carbon sources, making it pivotal for root development (Correa et al. 2005).

\section{CONCLUSION}

From the presented data of different parameters, it can be concluded that there are several pros \& cons of sucrose solution treatment on adventitious root growth of pineapple crown, such as for the emergence of root $\mathrm{T}_{1}$ (0 Day Drying $+2 \%$ sucrose) proved to be the best in case of early rooting and $\mathrm{T}_{2}$ (4 Day Drying + $2 \%$ sucrose), $\mathrm{T}_{4}$ (4 Day Sun Drying $+4 \%$ sucrose) seems to be undesirable. On the other hand, no such influence or impactwas seen by any treatments on the number of leaves \& number of damaged leaves. It clearly shows that all the concentrations of sucrose, including treatments $\mathrm{T}_{5}(0$ Day Sun Drying + 0\% sucrose) \& $\mathrm{T}_{6}$ (4 Day Drying + $0 \%$ sucrose) are not suitable for the growth of leaves in the pineapple crown. Now, in the case of several number of roots, T3 (0 Day Drying $+4 \%$ sucrose) has given the best result \& T2 (4 Day Drying + $2 \%$ sucrose) proved to be the suppressed on. In comparison, $\mathrm{T}_{6}$ (4 Day Drying $+0 \%$ sucrose) shows the highest root diameter growth, and $\mathrm{T}_{1}(0$ Day Drying $+2 \%$ sucrose) gives the minimum diameter growth among all. On the contrary that $\mathrm{T}_{1}(0$ Day Drying $+2 \%$ sucrose) is justified to be the excellent treatment for the elongation of the root were $\mathrm{T}_{4}(4$ Day Drying $+4 \%$ sucrose) displayed the opposite outcome. Hence, from the overall experiment, it can be concluded that $\mathrm{T}_{3}(0$ Day Drying $+4 \%$ sucrose) proved to be the best in the case of all the parameters measured.

\section{REFERENCES}

Calamar, A. and De Klerk, G.J. 2002. Effect of sucrose on adventitious root regeneration in apple. Plant Cell, Tissue Organ Cult., 70(2): 207-212.

Chenevard, D., Jay-Allemand, C., Gendraud, M. and Frossard, J.S. 1995. The effect of sucrose on the development of hybrid walnut microcuttings (Juglans nigra $x$ Juglans regia). Consequences on their survival during acclimatization. In Annales des sciences forestières, 52(2): 147-156. EDP Sciences.

Correa, L.D.R., Paim, D.C. and Schwambach, J. 2005. FettNetoAG. Carbohydrates as regulatory factors on the rooting of Eucalyptus saligna Smith and Eucalyptus globulus Labil. Plant Growth Regul., 45: 63-73.

Dey, K., Ghosh, A., Mani, A., Bauri, F.K. and Dey, A.N. 2017. Root generation of Karonda (Carissa carandas L.) cuttings in response of sucrose and IBA. J. Pharmacogn. Phytochem., 6(6): 803-806.

Eguchi, T. and Yoshida, S. 2008. Effects of application of sucrose and cytokinin to roots on the formation of tuberous roots in sweetpotato (Ipomoea batatas (L.) Lam.). Plant Root, 2: 7-13.

Elazab, D.S. and Shaaban, M.M. 2015. The impact of sucrose concentration on root growth and development in fig (Ficus carica L.) in vitro. Assiut. J. Agric. Sci., 46(6): 67-75.

Gomez, K.A. and Gomez, A.A. 1984. Statistical Procedures for Agricultural Research (2nd Ed.). Wiley-Inter Science Publication,) New York, USA.

Kesari, V., Das, A. and Rangan, L. 2010. Effect of genotype and auxin treatments on rooting response in stem cuttings of CPTs of Pongamiapinnata, a potential biodiesel legume crop. Curr. Sci., pp. 1234-1237.

Sheoran, O.P., Tonk, D. S., Kaushik, L.S., Hasija, R.C. and Pannu, R.S. 1998. Statistical Software Package for Agricultural Research Worker. Recent Advances in information theory, Statistics and Computer Applications by D.S. Hooda and R.C. Hasija, Department of Mathematics Statistics, CCS HAU, Hisar, pp. 139-143.

Xuan, W., Zhu, F.Y., Xu, S.H., Huang, B.K., Ling, T.L., Qi, J.Y., Ye, M.B. and Shen, W.B. 2008. The Heme Oxygenase/ carbon monoxide system is involved in the auxin-induced cucumber adventitious rooting process. Plant Physiol., 148: 881-893. 
